\title{
Human Nose Might Be Involved in Cooling of the Brain
}

\author{
Susumu Mukai \\ Otorhinolaryngology, Cervico-Facial Surgery, Mukai Clinic, Yamato, Kanagawa, Japan \\ Email: s-mukai@da2.so-net.ne.jp
}

Received 28 May 2015; accepted 7 July 2015; published 10 July 2015

Copyright (C) 2015 by author and Scientific Research Publishing Inc.

This work is licensed under the Creative Commons Attribution International License (CC BY). http://creativecommons.org/licenses/by/4.0/

c) (i) Open Access

\begin{abstract}
I have reached the conclusion that the human nose might be involved in cooling of the brain. In this report, I first describe the clinical observations about ankyloglossia with deviation of the epiglottis and larynx (ADEL) with regard to sleep that I have made during my 30 years of otorhinolaryngological experience. Then I describe the physiology of the nose. Next I quote from reports on paradoxical sleep, or REM sleep, from Kitamura K (2009) and Jouvet M (1992). Finally, I present the conclusion that nasal respiration is indispensable to a deep and sound sleep that refreshes humans and promotes vitality.
\end{abstract}

\section{Keywords}

Nose, Sleep, Paradoxical Sleep, REM, ADEL, CGL, EVo

\section{Introduction}

Historically, ankyloglossia was thought to be the result of suckling problems [1]-[3].

But there is a condition where ankyloglossia is accompanied by upward and forward deviation of the epiglottis and larynx. I was first to report this condition ankyloglossia with deviation of the epiglottis and larynx (ADEL) [4]-[6]. In ADEL the tongue is attached to the mandibular bone ventrally and it is attached to the floating hyoid bone caudally. As a result, the epiglottis and larynx are pulled upward and forward. The tongue is restricted and the airway between the nasal choanae and the larynx is deviated.

This condition causes multiple symptoms in humans, and these symptoms change with age. In babies, there are suckling problems, suffocation during suckling, hard crying, cold extremities, shallow sleep, digit sucking, etc. [7]. Symptoms in childhood include poor posture, fatigability, dependency, moving about while sleeping, etc. [8], and those of adults are fatigability, daytime sleepiness, sleep apnea, hypopnea, snoring, etc. [5].

I developed two operations for ADEL. The first was correction of the glosso-larynx (CGL) [9]. The aim of 
CGL is to cut the center of the sublingual membrane whether or not a lingual frenulum is present. Then two to three bundles of both genioglossus muscles are cut. As a result movements of the tongue increase and the epiglottis and larynx move downward and dorsally. The face of the vocal folds is positioned in front of the nasal choanal opening. The airstream between the nose and the larynx flows smoothly.

After CGL the following changes were observed: increased respiratory rate, vital capacity, forced expiratory volume and expansions of both the hypopharynx and trachea. Immediately after CGL, babies' faces changed to a more healthy color and their cry became clearer and louder [10].

Then I developed the expansion of the vestibular oris (EVO) for ADEL, which is accompanied by incomplete development of the maxillary bone as well as facial muscles. The aims of EVO are to decrease the ventral forces of the depressor septi nasi muscle from the maxillary bone, promote lateral growth of the maxillary bone, and widen the nasal cavities. The method is to cut the upper lingual frenulum, then detach the depressor nasi muscles from the maxillary bone to the level of the junction of nasal septum and maxillary bone [11].

After EVO, the following changes were observed: nasal widening, decreased nasal airway resistance and increased nasal airflow, and esthetic facial changes [11]-[13]. The expansion of the nostrils, rise of the angulus oris and widening of both optic fissures are observable just after EVO.

After both surgeries, in infants suckling problems, hard crying, shallow sleep, and mother-baby communications were ameliorated greatly. In adults, respiration became easier and the body relaxed. All who underwent these operations revealed improvements in sleep.

I developed Z-pharyngoplasty (ZPP) to expand the oropharynx instead of uvulopalatopharyngoplasty (UPPP) for heavy snorers. The uvula is cut during UPPP. The uvula is a sensor of swallowing to avoid accidental ingestion when eating. In ZPP the uvula is untouched and oropharynx opens wider than with UPPP [14] [15].

Adeno-tonsillectomies were often performed in children with sleep disorders and/or apnea accompanied by ADEL and by hyper adenoid vegetation and tonsillar hypertrophy. After these operations it was reported that the children slept quietly and did not move around during sleep. Also, they awakened earlier than before the operations [16]-[18]. These observations revealed that the benefits of sleep are not necessarily related to the length of sleep time. Sleep even in shorter durations can increase vitality.

\section{Nose}

The wing of the nose surrounds the nasal vestibulum, nasal septum, and nares, which comprises the nasal valve. The most important component of nasal airflow resistance is the nasal valve. Cottle et al. reported that the main airflow regulator in the (leptorrhine) nose of Caucasians is the nasal valve [19]-[21]. The airflow resistance effect of decongestion by turbinates in leptorrhine and platyrrhine noses did not demonstrate significant differences.

When sniffing, the nostrils open and narrow synchronously with narrowing and widening of the vocal folds [22]-[25]. If an individual has lost the sense of smell, the sniffing movements of both nostrils and vocal folds disappear [22]-[25]. Also, when sniffing, the direction of the nasal airflow changes towards the olfactory area, and the airflow in this area increases [26]. These observations suggest that the nasal valves control nasal airflow.

\section{Sleep}

If an animal does not sleep, or is deprived of sleep, it dies. Sleep is regulated by the brain and is essential for maintenance of the brain. Although the brain comprises only $2 \%$ of the body weight, the brain consumes $20 \%$ of the total body energy. Especially the consumption of glucose increases during paradoxical, or REM, sleep. That is, the consumption of energy increases during paradoxical (REM) sleep and, as a result, the body temperature rises. When the rise in body temperature is restrained, paradoxical (REM) sleep can continue for a longer period. The tension in antigravity muscles disappears during paradoxical (REM) sleep. This sleep is physically the deepest [27] [28].

The brain neural network is efficiently reorganized during paradoxical (REM) sleep. Repairs, fixation of memories, and adaptation to the circumstances encountered during the daytime are done efficiently by the brain according to innate programming. In other words, repairs are made during dreaming. Dreaming is essential for establishing the individuality that makes one individual different from others [27] [28]. In addition to the activation processes taking place in the brain, growth hormone is secreted and memories are fixed during paradoxical (REM) sleep [27] [28]. Maintaining the vitality and activation of the immune system might also be regulated during paradoxical (REM) sleep. 
Heat radiation takes place from the skin of the extremities during paradoxical (REM) sleep. It has been said that when the body temperature decreases, the length of paradoxical (REM) sleep increases. That is, control systems regulating sleep are closely related to body temperature [27] [28].

Sleep apnea, snoring, insomnia, and light sleep are observed when patients have a nasal obstruction. In addition to these symptoms, enuresis and poor memory are observed in children with nasal obstructions [16] [17] [29]. These children are apt to be dependent and have underdeveloped egos. They are apt to be left behind and are also dependent even after they grow up [16] [17] [29].

Rolling about during sleep shows that an individual cannot enter into deep sleep. Presumably such persons have short paradoxical (REM) sleep. These observations might be the same in adult patients with sleep disorders.

Patients with nasal obstruction complain that they feel dull and have a vague affect during the day even if they have had sufficient sleep. Although their $\mathrm{SpO} 2$ is within the normal average range while sleeping, the brain might not be activated during sleep if such persons only have short paradoxical (REM) sleep. It may be possible that refreshment of the brain during sleep is imperfect in those with a nasal obstruction. Activation of the brain might be imperfect during sleep. Brain temperature probably rises during sleep if nasal obstruction is present, and such arise will keep an individual awake.

Children that have recovered from EVO, CGL, and adeno-tonsillectomy sleep silently and without motion. They become self-assertive. They more clearly show their likes and dislikes. Their post-operative changes show that they enter deep and sound sleep [17] [30]. In other words, they have longer periods of paradoxical (REM) sleep. Their genetic programs work to recover their individuality so that they are unique individuals in their dreams or during paradoxical (REM) sleep.

In humans, the neurocranium is located at the top of the nose. The nose is located between the neurocranium and the respiratory cranium. Development of the neurocranium in humans is faster than that of the respiratory cranium. It has almost reached adult size at the age of seven years [31]. On the contrary, the end of growth of the respiratory cranium is when the wisdom teeth appear [32].

After airflow enters into the nasal cavity via nasal valves, it becomes turbulent and expands through the nasal cavities to the posterior choanae. The nasal cavities are lined by ciliated, pseudostratified columnar epithelium. It has been noted that the membrane of middle and inferior turbinates is, in its abundance of vascular patterns, sometimes mistaken by pathologists for neoplasms such as a haemangioma or angiofibroma [33].

It was said that except for smelling, the role of the human nose is to clean, humidify, and warm the air that flows into the lung. Humidification and warming are nothing but heat radiations. The walls between the cranium and nose consist of thin, hard, and flat cavernous bone (Figure 1 and Figure 2). These anatomical structures are

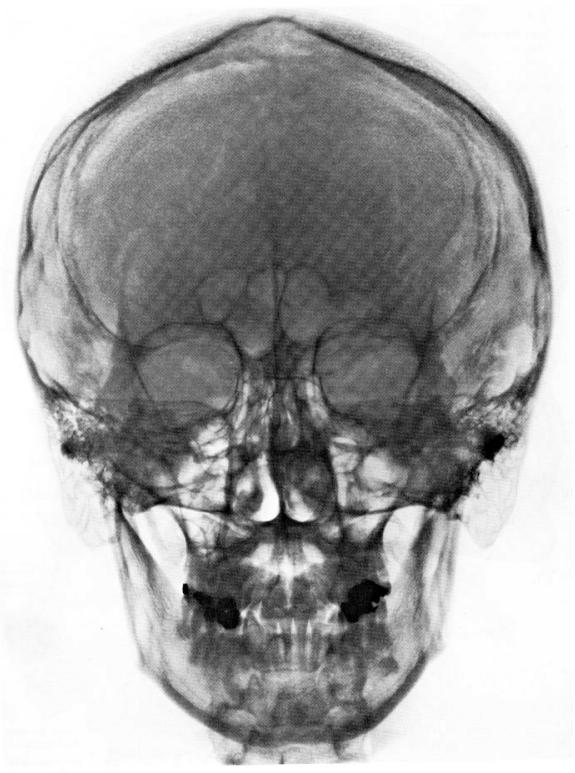

Figure 1. Frontal view of the cranium. The walls between the cranium and nose consist of thin, hard, and flat cavernous bone. 


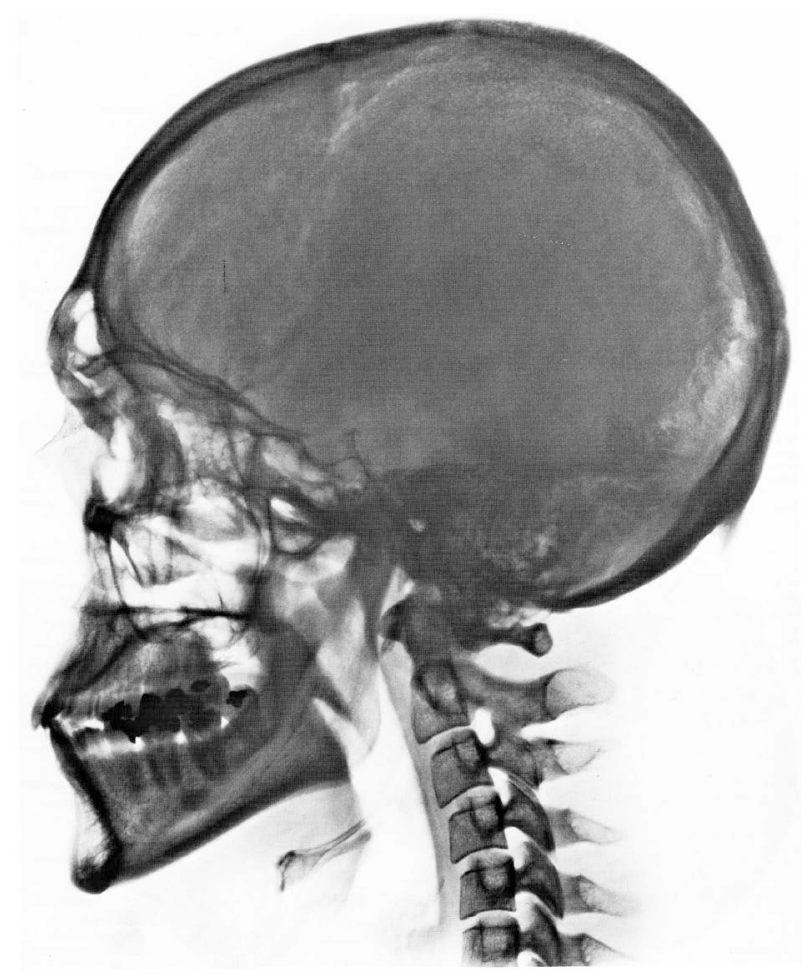

Figure 2. Lateral view of the cranium. The anatomical structures of the nose are well suited for heat exchange.

well suited for heat exchange. The paranasal sinuses might also be useful for cooling of the brain.

Through the heat exchanges that take place in the nose, humans get sufficient paradoxical (REM) sleep.

\section{Conclusion}

It is concluded that the most important function of the human nose might be cooling of the brain during sleep.

\section{References}

[1] Paré, A. (1970) De l’empeschementet retraction de la langve. Amboise Paré; Oevres Complétes. J. F. Malgaigne. Genève, Slatkine Reprinte. II: 455-456.

[2] Paré, A. (2010) The Book of Surgery. Uo, G., Ed., Linker, W. and Womack, N., Trans., The University of Georgia Press, Athens, 1575.

[3] Loux, F. (1978) Le jeune enfant et son corps dans la médecine traditionnelle. Flammarion, Paris.

[4] Mukai, S., Mukai, C. and Asaoka, K. (1991) Congenital Ankyloglossia with Deviation of the Epiglottis and Larynx. Annals of Otolaryngology, 100, 1-20.

[5] Mukai, S., Mukai, C. and Asaoka, K. (1993) Congenital Ankyloglossia with Deviation of the Epiglottis and Larynx: Symptoms and Respiratory Function in Adult. Annals of Otology, Rhinology \& Laryngology, 102, 620-624. http://dx.doi.org/10.1177/000348949310200810

[6] Mukai, S. and Mukai, C. (1991) New Disease with Ankyloglossia and Dislocation of the Epiglottis and of the Larynx-Dyspnea of the Newborn and Suckling Infants. In: Takishima, H., Ed., Advances in the Biosciences, Pergamon Press, New York, 191-193.

[7] Mukai, S., Mukai, C., Asaoka, K. and Nagasugi, S. (1992) Digit Sucking. Lancet, 339, 1545-1546. http://dx.doi.org/10.1016/0140-6736(92)91316-Z

[8] Mukai, S., Mukai, C., Asaoka, K., Nagasugi, S. and Ogiyam, M. (1991) Postoperative Changes in Infant with ADEL. Zetuyuchalushou Kenkyuukai Kaiho (Annals ADEL), 1, 35-45. (In Japanese with English Abstract)

[9] Mukai, S., Mukai, C. and Asaoka, K. (1990) Congenital Ankyloglossia with Deviation of the Epiglottis and LarynxRespiratory Insufficiency of the Children. Journal of Clinical Otolaryngology (Kyoto), 83, 1043-1065. (In Japanese 
with English Abstract)

[10] Mukai, S. (1995) Changes after Correction of the Epiglottis and Larynx (CGL). Zetuyuchakusho Kennkyuukai Kaiho, 5, 82-92. (In Japanese)

[11] Mukai, S. and Nitta, N. (2004) Expansion of the Vestibular Oris (EVO). Nihon Zetuychakusho Gakkai Kaishi (Annals $A D E L)$, 12, 1-9. (In Japanese)

[12] Mukai, S. (2010) Expansion of the Vestibular Oris (EVO)—Esthetic Facial Changes and Expansion of the Nasal Cavity. Nihon Zetuychakusho Gakkai Kaishi (Annals ADEL), 16, 32-41.

[13] Mukai, S. (2013) Dilatation of the Nasal Valve by Expansion of the Vestibular Oris (EVO). Health, 5, 21-25. http://dx.doi.org/10.4236/health.2013.58A2004

[14] Mukai, S., Mukai, C. and Nitta, M. (2000) Function of the Uvula and Z-Pharyngoplasty. Psychiatry and Clinical Neurosciences, 54, 346-347. http://dx.doi.org/10.1046/j.1440-1819.2000.00708.x

[15] Mukai, S., Mukai, C. and Nitta, M. (2000) Function of the Uvula and Z-Pharyngoplasty. Practica Oto-Rhino-Laryngologica, 93, 31-38. (In Japanese with English Abstract) https://www.jstage.jst.go.jp/article/jibirin1925/93/1/93_1_31/_article

[16] Mukai, S., Yamamoto, W., Suzuki, M. and Asaoka, K. (1980) Postoperative Headache in Oto-Rhino-Laryngology: Especially on after Nasal Obstruction. Nihon Jibiinkoka Gakkai Kaiho, 83, 960-965. http://dx.doi.org/10.3950/jibiinkoka.83.960

[17] Mukai, S. (2013) Vicissitude of Curetted Adenoid Vegetations. International Journal of Clinical Medicine, 4, 251-256. http://www.scirp.org/journal/ijcm http://dx.doi.org/10.4236/ijcm.2013.45044

[18] Mukai, S. (2011) Tonsils Increases in Weight during Growth, Moreover There Are Gender Differences. Optimumtime of Tonsilectomy Is between Two to Four. Zetuyuchakushogakkaishi, Annals of the Ankyloglossia with Deviation of the Epiglottis and Larynx, 17, 19-26. (In Japanese)

[19] Cottle, M.H. (1955) The Structure and Function of the Nasal Vestibule. Archives of Otolaryngology-Head \& Neck Surgery, 62, 173-181. http://dx.doi.org/10.1001/archotol.1955.03830020055011

[20] Bridger, G.P. (1970) Physiology of the Nasal Valve. Archives of Otolaryngology—Head \& Neck Surgery, 92, 543-553. http://dx.doi.org/10.1001/archotol.1970.04310060015005

[21] Heinberg, C.E. and Kern, E.B. (1973) The Cottle Sign: An Aid in the Physical Diagnose of Nasal Airflow Disturbances. 3rd Congress of the International Rhinologic Society, Bordeaux, 89-94.

[22] Mukai, S. (1989) Larynbgeal Movements during Wind Instruments Play. Nihonn Jibiinnkouka Gakkaihou, 92, $260-270$. (Japanese with English Abstract) http://dx.doi.org/10.3950/jibiinkoka.92.260

[23] Mukai, S. (1989) Vocal Cord Adduction While Sniffing. Archives of Otolaryngology—Head \& Neck Surgery, 115, 1362-1366. http://dx.doi.org/10.1001/archotol.1989.01860350096023

[24] Mukai, S., Mukai, C. and Suzuki, I., Eds. (1989) Dysosmia with Vocal Cord Paralysis during Sniff, Abstract 740. 14th World Congress of Otorhinolaryngology Head and Neck Surgery, Madrid, 10-15 September 1989.

[25] Mukai, S., Mukai, C. and Suzuki, I., Eds. (1989) Vocal Cords Adduct during Sniff (Abstract), Video. 14th World Congress of Otorhinolaryngology Head and Neck Surgery, Madrid, 10-15 September 1989.

[26] Ganong, W. (1993) Sniffing. In: Ganog, W., Ed., Review of Medical Physiology, 16th Edition, Appleton \& Lange, Norwalk, 168-169.

[27] Jouvet, M. (1992) Le sommeil et le rêve. Kitahama, K., Trans., Kinokuniya Shoten Ltd., Tokyo. (In Japanese)

[28] Kitahama, K. (2009) Brain and Sleep. Asakura-Shoten Ltd., Tokyo. (In Japanese)

[29] Mukai, S. (1978) Effect of Nasal Packing on the Respiration (Japanese with English abstract). Nihon Jibiinkoka Gakkai Kaiho, 81, 443-447. http://dx.doi.org/10.3950/jibiinkoka.81.443

[30] Mukai, S. (2013) Tonsils Increase in Weight during Growth. International Journal of Clinical Medicine, 4, $222-227$. http://www.scirp.org/journal/ijcm http://dx.doi.org/10.4236/ijcm.2013.44039

[31] Enlow, D.H. and Hans, M.G. (1996) Essentials of Facial Growth. WS Saunders Co., Philadelphia, 1-240.

[32] Takahashi, R. (1987) Why the Nose Is Center of the Face. Tsukijishokann Ltd., Tokyo. (In Japanese)

[33] Michaels, L. and Hellquist, H.B. (2001) Histology of the Nose. In: Michaels, L. and Hellquist, H.B., Eds., Ear, Nose and Throat Histopathology, 2nd Edition, Springer-Verlag London Ltd., London, 139-140. 